\title{
Does Farnesoid X receptor (FXR) Have a Role in NAFLD Progression ? Shereen Fathy Mahmoud ${ }^{1}$, Dina Sweed ${ }^{2}$ Esraa Karman*², Nancy Youssef Asaad ${ }^{1}$, Nanis Shawky Holah ${ }^{1}$ \\ ${ }^{1}$ Pathology Department, Faculty of Medicine, ${ }^{2}$ Pathology Department, National Liver Institute, Menofia University, Egypt \\ *Correspondence: Esraa Karman, Mobile: 02001098086080, E-mail: esraa.karman92@ gmail.com
}

\begin{abstract}
Background: Non-alcoholic fatty liver disease (NAFLD) is the emerging cause of chronic liver disease. In addition, steatosis may lead to failure of obtaining sustained virological response after hepatitis $\mathrm{C}$ virus eradication. Therefore, there is a trend to identify effective strategies for managing hepatic steatosis. Farnesoid X receptor (FXR) agonists are reported to play a role in NAFLD treatment.

Objective: This study aimed to explore the immunohistochemical expression of FXR in NAFLD spectrum in association with the clinicopathological data.

Material and method: This was a retrospective study including 50 cases of NAFLD and 23 cases of normal liver. The NAFLD group was subdivided into 11 cases of NAFL (simple steatosis) and 39 cases of non-alcoholic steatohepatitis (NASH). Results: Hepatocyte FXR nuclear expression was significantly decreased in NASH group ( $\mathrm{P}=0.001)$ with no significant decrease in NAFL group compared to normal liver $(\mathrm{P}=0.149)$. Bile duct FXR expression was significantly lower in NAFL group compared to normal liver $(\mathrm{P}=0.009)$ to reach the lowest level in NASH group $(\mathrm{P}=0.017)$. In NAFLD group, there was an inverse correlation between hepatocyte FXR nuclear expression and the ALT/AST ratio $(\mathrm{r}=-0.349$ and $\mathrm{P}=0.013)$. However, hepatocyte FXR nuclear expression was significantly associated with moderate grade of steatosis and severe fibrosis $(\mathrm{P}=0.044$ and $\mathrm{P}=0.033$, respectively).

Conclusion: Hepatocyte FXR nuclear expression showed a stepwise decrease in its expression from normal to NASH passing with NAFL. Therefore, FXR has a protective role against NAFLD progression. Elevated liver enzymes could be used as a non-invasive method for monitoring FXR agonists' efficacy.
\end{abstract}

Keywords: ALT/AST ratio, FXR, NAFLD spectrum.

\section{INTRODUCTION}

Non-alcoholic fatty liver disease (NAFLD) is considered an emerging issue worldwide with an alarming rising prevalence. The highest prevalence rates (nearly 30\%) has been reported from Middle East and South American countries with a much lower prevalence rate in Africa (13\%) (1). NAFLD is a spectrum of liver disease including simple steatosis > $5 \%$, non-alcoholic steatohepatitis (NASH), fibrosis, cirrhosis, and hepatocellular carcinoma (HCC) ${ }^{(2)}$. The fundamental criteria is the presence of steatosis in the absence of any other causes for liver diseases; such as alcohol consumption, chronic viral hepatitis and autoimmune hepatitis ${ }^{(3)}$. NAFLD is considered the hepatic manifestation of metabolic syndrome and commonly associated with obesity, insulin resistance, type 2 diabetes, dyslipidemia, hypertriglyceridemia, and hypertension ${ }^{(4)}$. Therefore, a global trend reached a final consensus that NAFLD terminology should be changed to metabolic associated fatty liver disease (MAFLD) ${ }^{(5)}$. Because of the rising global concern towards NAFLD as the coming leading cause of endstage liver disease, HCC and liver transplantation, a considerable effort has to be paid to its prevention and available treatment ${ }^{\left({ }^{6}\right)}$.

Farnesoid X receptor (FXR), also known as $\mathrm{NR} 1 \mathrm{H} 4$, is a member of the nuclear receptor superfamily. It is highly expressed in the liver, intestine, kidney and adrenals ${ }^{(7)}$.
Under physiological condition, bile acids (BAs) are endogenous ligands of FXR playing a crtitical role in elimination of cholesterol, regulation of glucose and lipid metabolism, and reduction of inflammation and fibrosis. FXR is located in cytoplasm of cholangiocytes and hepatocytes and aids in BA formation and regulation through different pathways ${ }^{(8)}$. Upon activation, FXR is translocated to the nucleus, forms a dimer and binds to hormone receptor element downregulating the expression of certain genes. In addition, the regulatory role of FXR in glucose and lipid metabolism via activation of de novo lipogenesis pathway through induction of liver $\mathrm{X}$ receptor (LXR) and Sterol regulatory element binding protein 1c (SREBP1c) ${ }^{(7,9)}$. Low hepatic FXR expression is reported as a risk factor in the development of NASH (10, 11). Furthermore, FXR is involved in both the adaptive and innate immune response associated with chronic inflammation of NASH ${ }^{(11)}$. Ongoing clinical trials using FXR agonists might represent a promising therapeutic strategy in the future to prevent and treat NASH ${ }^{(12)}$. In view of limited previous studies exploring the expression of FXR protein on NAFLD patients.

Therefore, we aimed to study the immunohistochemical (IHC) expression of FXR on liver tissue from NAFLD cases with different dissease 
spectrum and to compare its expression with the available clinicopathological data.

This could aid in predicting the possible long term impact of FXR agonists exposure on the progression of the disease.

\section{PATIENTS AND METHODS}

This is a retrospective, case control study including 73 cases divided into two groups; 50 cases of NAFLD and 23 of normal liver tissues (obtained from potential donor of liver transplantation), depicted in figure $(1, \mathrm{~A})$. The NAFLD group was further allocated into two subgroups: 11 cases with NAFL and 39 cases with NASH). Formalin-fixed, paraffin embedded (FFPE) specimens were collected from the archive of the Pathology Department, National Liver Institute, Menofia University as a part of the standard clinical management of the patients. Clinical and laboratory data were collected from patients' medical records. Cases with positive drug history, chronic viral hepatitis or autoimmune disease had been excluded from the study.

Grading and staging of NAFLD cases were done according to steatosis, activity and fibrosis scoring (SAF scoring) (13). Steatosis was scored into three grades according to the percentage of fat cells. Hepatocyte ballooning and lobular inflammation were graded into score 1 and 2 , and a final activity score was obtained by the sum of both scores. Hepatic fibrosis was assessed by Masson trichrome stain and staged from 1 to 4 according to the distribution and severity of fibrosis. In addition, we assessed bile duct injury and proliferation in order to link the impact of bile duct injury on the expression of hepatocyte FXR.

\section{Ethical approval:}

The study was approved from the Institutional Review Board (IRB) of the National Liver Institute (NLI) and Faculty of Medicine, Menoufia University.

The IHC staining and assessment of FXR antibody: Rabbit polyclonal FXR primary antibody (Ref; ab235094) was obtained from Abcam, Cambridge, UK. High PH tris-EDTA antigen retrieval solution (Dako, Ref K8000, Glostrup, Denmark) was carried out for 20 minutes heating followed by cooling for 20 minutes. Sections treated with primary antibody diluted in Dako antibody diluent at concentration of (1:75) and incubated overnight at $4^{\circ} \mathrm{C}$. Human kidney was used as a positive control. Negative control by omitting primary antibody was included in each run.

The expression of FXR was assessed in hepatocytes and bile ducts and considered positive if any nuclear brownish expression was detected ${ }^{(14,15)}$. In addition, hepatocyte cytoplasmic expression was observed in hepatocytes together with the nuclear expression and was also assessed (16). FXR antibody expression was assessed according to the Histoscore $(\mathrm{H}$ score) system. A final score (0 to 300) was obtained by multiplying the staining intensity $(0-3)$ by the percentage of stained cells ${ }^{(\mathbf{1 7})}$.

\section{Statistical Analysis}

Statistical analysis was carried out using Statistical Package for the Social Sciences (SPSS) program for windows, version 20, SPSS Inc., Chicago, Illinois, USA. The Kolmogorov-Smirnov test was used to verify the normality of distribution. Significance of the obtained results was judged at the $5 \%$ level.

Chi-square test was used to compare between categorical variables and Monte Carlo when more than $20 \%$ of the cells have expected count less than 5 . Student t-test and F-test (ANOVA) were used for normally distributed quantitative variables. Post Hoc Test (Dunn's) was used for multiple comparisons. Mann Whitney and Kruskal Wallis tests were used to compare between abnormally distributed quantitative variables. In addition, Pearson and Spearman coefficient were used to correlate between two quantitative variables. Two tailed $\mathrm{P}$-value is considered statistically significant when it is $\leq 0.05$.

\section{RESULTS}

\section{The clinicopathological data of NAFLD group:}

The median age of the studied NAFLD cases was 29 years old with median serum ALT/AST ratio of 1.19 (0.88-1.44). NAFLD patients were allocated into two subgroups 11 cases of NAFL, 22\% (Fig. 1, B) and 39 of NASH, $78 \%$ (Fig. 1, C). The mean percent of steatosis \pm SD was $37.40 \pm 22.73$. Ballooning change and lobular inflammation were seen in $88 \%$ and $98 \%$ of cases, respectively. The stage of fibrosis was mild in $64 \%$ and severe in $16 \%$ of cases. The details of clinicopathological data of NAFLD group were illustrated in table (1). 
Table (1): The clinicopathological data of NAFLD cases.

\begin{tabular}{|c|c|c|}
\hline Variables & \begin{tabular}{|l|} 
No. \\
\end{tabular} & $\%$ \\
\hline $\begin{array}{c}\text { Age (years) } \\
\text { Min. - Max. } \\
\text { Mean } \pm \text { SD. } \\
\text { Median (IQR) }\end{array}$ & $\begin{array}{l}18-57 \\
31.40 \pm 10.65 \\
29(24-36)\end{array}$ & \\
\hline 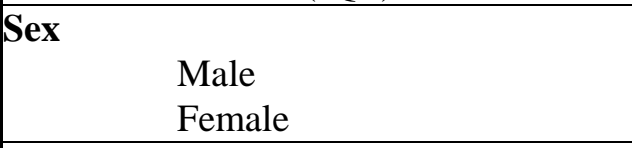 & $\begin{array}{l}28 \\
22\end{array}$ & $\begin{array}{l}56 \\
44\end{array}$ \\
\hline $\begin{array}{c}\text { ALT/AST ratio } \\
\\
\text { Mean } \pm \text { SD. } \\
\text { Median (IQR) } \\
\end{array}$ & $\begin{array}{l}1.26 \pm 0.3 \\
1.19\end{array}$ & \\
\hline $\begin{array}{l}\text { Steatosis } \% \\
\qquad \begin{array}{l}\text { Mean } \pm \text { SD. } \\
\text { Median (IQR) }\end{array}\end{array}$ & $\begin{array}{l}37.40 \pm 2.73 \\
40\end{array}$ & \\
\hline $\begin{array}{c}\text { Steatosis grade } \\
\text { Mild } \\
\text { Moderate } \\
\end{array}$ & $\begin{array}{l}40 \\
10\end{array}$ & $\begin{array}{l}80 \\
20 \\
\end{array}$ \\
\hline $\begin{array}{c}\text { Lobular inflammation } \\
\text { Absent } \\
\text { Present } \\
\end{array}$ & $\begin{array}{l}1 \\
49 \\
\end{array}$ & $\begin{array}{l}2 \\
98 \\
\end{array}$ \\
\hline \begin{tabular}{|l} 
Fibrosis \\
\\
\\
Absent \\
Mild \\
Severe \\
\end{tabular} & $\begin{array}{r}10 \\
32 \\
8 \\
\end{array}$ & $\begin{array}{c}20 \\
64 \\
16 \\
\end{array}$ \\
\hline $\begin{array}{c}\text { Bile duct injury and proliferation } \\
\text { Absent } \\
\text { Present }\end{array}$ & $\begin{array}{l}40 \\
10\end{array}$ & $\begin{array}{l}80 \\
20\end{array}$ \\
\hline
\end{tabular}

ALT: Alanine transferase, AST: Aspartate transferase, NAFLD: Non-alcoholic fatty liver disease, NASH: Non-alcoholic steatohepatitis.

\section{The IHC expression of FXR in the studied groups:} (Table 2)

Regarding normal liver tissue cases, all cases $(100 \%)$ showed positive hepatocyte nuclear expression (median $\mathrm{H}$ score 230) and bile duct nuclear expression (median H score was 190) as shown in figure $(1, \mathrm{D})$. In NAFL group, hepatocytes showed positive FXR nuclear staining in $100 \%$ of cases with a median $\mathrm{H}$ score of 175 as shown in figure $(1, E)$. On the other hand, bile duct positive expression was detected in $84 \%$ of cases with a median H. score of 120 .

There was a positive correlation between FXR hepatocyte nuclear expression and bile duct expression within NAFL group $(r=0.404$ and $p=0.004)$.

FXR hepatocyte expression declined in a stepwise fashion from normal to NASH passing through NAFL group. There was no significant difference between NAFL and normal liver tissue groups regarding FXR hepatocytes nuclear expression $(\mathrm{P}=0.149)$. However, low FXR hepatocyte nuclear expression was significantly observed in NASH group compared to normal liver tissue group $(\mathrm{P}=0.001)$ as shown in figure $(1, \mathrm{~F})$.

Similarly, there was a significant decrease in FXR bile duct expression in NAFL and NASH groups compared to normal group $(\mathrm{P}=0.009$ and $\mathrm{P}=0.017$, respectively).

Furthermore, there was no significant difference between NAFL and NASH groups regarding hepatocyte or bile duct FXR expression $(\mathrm{P}=0.706$, $\mathrm{P}=0.339$, respectively). 
Table (2): Comparison between H score of immunohistochemical expression of FXR in the studied groups.

\begin{tabular}{|c|c|c|c|c|c|}
\hline \multirow[t]{2}{*}{ Variables } & \multirow{2}{*}{$\begin{array}{l}\text { Normal } \\
(n=23)\end{array}$} & \multicolumn{2}{|c|}{$\begin{array}{c}\text { NAFLD } \\
(\mathbf{n}=50)\end{array}$} & \multirow{2}{*}{$\begin{array}{l}\text { Test of } \\
\text { sig. }\end{array}$} & \multirow[t]{2}{*}{ P-value } \\
\hline & & Simple steatosis $(\mathrm{n}=11)$ & NASH $(n=39)$ & & \\
\hline \multicolumn{6}{|c|}{ FXR hepatocyte expression } \\
\hline Min. - Max. & $55.0-260.0$ & $\begin{array}{ll}120.0 & 260.0 \\
\end{array}$ & $95.0-260.0$ & \multirow{3}{*}{$\begin{array}{c}\mathrm{F}= \\
6.770^{*}\end{array}$} & \multirow{3}{*}{$0.002^{* *}$} \\
\hline Mean \pm SD. & $212.6 \pm 49.54$ & $181.36 \pm 34.65$ & $169.10 \pm 44.81$ & & \\
\hline Median (IQR) & $230(200-245)$ & $175(165-195)$ & $170(125-200)$ & & \\
\hline Sig. bet. groups. & \multicolumn{3}{|c|}{$\mathrm{p}_{1}=0.149, \mathrm{p}_{2}=0.001^{*}, \mathrm{p}_{3}=0.706$} & & \\
\hline \multicolumn{6}{|c|}{ FXR bile duct expression } \\
\hline Min. - Max. & $0.0-280.0$ & $0.0-270.0$ & $0.0-270.0$ & \multirow{3}{*}{$\begin{array}{c}\mathrm{H}= \\
8.605^{*}\end{array}$} & \multirow{3}{*}{$0.014^{*}$} \\
\hline Mean \pm SD. & $177.17 \pm 72.50$ & $108.18 \pm 86.5$ & $133.3 \pm 73.76$ & & \\
\hline Median (IQR) & $\begin{array}{c}190.0(140.0- \\
227.5) \\
\end{array}$ & $120.0(40.0-145.0)$ & $130.0(100.0-185.0)$ & & \\
\hline Sig. bet. groups. & \multicolumn{3}{|c|}{$\mathrm{p}_{1}=0.009^{*}, \mathrm{p}_{2}=0.017^{*}, \mathrm{p}_{3}=0.339$} & & \\
\hline
\end{tabular}

NAFLD: Non-alcoholic fatty liver disease, NASH: Non-alcoholic steatohepatitis,

$\chi^{2}$ : Chi square test, MC: Monte Carlo, F: ANOVA test, H: Kruskal Wallis test,

*: Statistically significant at $\mathrm{p} \leq 0.05$.

**: Highly significant at $\mathrm{p} \leq 0.01$.

$\mathrm{p}$ : $\mathrm{p}$ value for comparing between Normal and NAFLD groups.

p1: $p$ value for comparing between Normal and simple steatosis groups.

$\mathrm{p}_{2}$ : $\mathrm{p}$ value for comparing between Normal and NASH groups.

$\mathrm{p}_{3}$ : $\mathrm{p}$ value for comparing between simple steatosis and NASH groups.

The association of FXR expression with the clinicopathological parameters of NAFLD group (n=50): (Table 3)

There was an inverse correlation between FXR hepatocyte nuclear expression and the serum ALT/AST ratio ( $\mathrm{r}=-0.349$ and $\mathrm{P}=0.013)$. On the other hand, there was a significant association between FXR nuclear hepatocyte overexpression and the moderate grade of steatosis, (Fig. 1, G) and high stage of fibrosis (Fig. 1, H) $(\mathrm{P}=0.044$ and $\mathrm{P}=0.033$, respectively). We also assessed the cytoplasmic expression of FXR in hepatocytes but there was no significant association with the available clinicopathological data (Data was not tabulated).
Regarding the impact of FXR bile duct expression, there was an inverse correlation between FXR bile duct expression and both patients' age and the serum ALT/AST ratio ( $\mathrm{r}=-0.285, \mathrm{P}=0.045$ and $\mathrm{r}=-0.354$ and $\mathrm{P}=0.012$, respectively). Also, there was a significant association between FXR bile duct overexpression and the moderate grade of steatosis and severe liver fibrosis $(\mathrm{P}=0.025$ and $\mathrm{P}=0.029$, respectively). In addition, FXR bile duct overexpression was significantly associated with the presence of bile duct injury and proliferation $(\mathrm{P}=0.008)$ as shown in figure 1 (I). 
Table (3): The association of FXR expression and the clinicopathological parameters in NAFLD group (n=50).

\begin{tabular}{|c|c|c|c|c|}
\hline \multirow[b]{2}{*}{ Variables } & \multicolumn{2}{|c|}{ FXR hepatocyte H score expression } & \multicolumn{2}{|c|}{ FXR bile duct $H$ score expression } \\
\hline & $\begin{array}{c}\text { Median } \\
(\text { Mean } \pm \text { SD })\end{array}$ & $\begin{array}{c}\text { Test of } \\
\text { Significance } \\
\text { \& p-value }\end{array}$ & $\begin{array}{c}\text { Median } \\
(\text { Mean } \pm \text { SD })\end{array}$ & $\begin{array}{c}\text { Test of } \\
\text { Significance } \\
\text { \& p-value } \\
\end{array}$ \\
\hline Age & & $\begin{array}{l}\mathrm{r}=0.177 \\
\mathrm{p}=0.220\end{array}$ & & $\mathrm{r}=-0.285 \mathrm{p}=0.045^{*}$ \\
\hline \multicolumn{5}{|l|}{ Sex } \\
\hline Male & $\begin{array}{c}175.0 \\
(177.9 \pm 44.08)\end{array}$ & \multirow{2}{*}{$\begin{array}{l}\mathrm{t}=1.133 \\
\mathrm{p}=0.263\end{array}$} & $\begin{array}{c}130.0 \\
(128.6 \pm 78.28)\end{array}$ & \multirow{2}{*}{$\begin{array}{l}\mathrm{U}=300.0 \\
\mathrm{p}=0.875\end{array}$} \\
\hline Female & $\begin{array}{c}160.0 \\
(164.1 \pm 40.70)\end{array}$ & & $\begin{array}{c}120.0 \\
(126.8 \pm 76.04)\end{array}$ & \\
\hline ALT/AST ratio & & $\begin{array}{l}\mathrm{r}=-0.349 \\
\mathrm{p}=0.013^{*}\end{array}$ & & $\begin{array}{l}\mathrm{r}=-0.354 \\
\mathrm{p}=0.012^{*}\end{array}$ \\
\hline \multicolumn{2}{|l|}{ Steatosis } & & \multirow{3}{*}{$\begin{array}{c}120.0 \\
(113.8 \pm 74.69) \\
180.0 \\
(184.0 \pm 57.58)\end{array}$} & \multirow{3}{*}{$\begin{array}{l}U=108.0^{*} \\
p=0.025^{*}\end{array}$} \\
\hline Mild & $\begin{array}{c}170.0 \\
(165.8 \pm 38.31) \\
\end{array}$ & $\mathrm{t}=2.067^{*}$ & & \\
\hline Moderate & $\begin{array}{c}190.0 \\
(196.0 \pm 52.75) \\
\end{array}$ & $\mathrm{p}=0.044^{*}$ & & \\
\hline \multicolumn{2}{|l|}{ Ballooning } & \multirow{3}{*}{$\begin{array}{l}\mathrm{t}=1.010 \\
\mathrm{p}=0.318\end{array}$} & \multirow{3}{*}{$\begin{array}{c}125.0 \\
(120.0 \pm 111.2) \\
130.0 \\
(128.9 \pm 72.29)\end{array}$} & \multirow{3}{*}{$\begin{array}{l}\mathrm{U}=122.0 \\
\mathrm{p}=0.782\end{array}$} \\
\hline Absent & $\begin{array}{c}190.0 \\
(188.3 \pm 45.35) \\
\end{array}$ & & & \\
\hline Present & $\begin{array}{c}170.0 \\
(169.6 \pm 42.44) \\
\end{array}$ & & & \\
\hline \multicolumn{2}{|c|}{ Lobular inflammation } & \multirow{3}{*}{ NA } & & \multirow[b]{3}{*}{ NA } \\
\hline Absent & - & & & \\
\hline Present & $\begin{array}{c}170.0 \\
(172.0 \pm 43.17)\end{array}$ & & $\begin{array}{c}130.0 \\
(128.0 \pm 77.30)\end{array}$ & \\
\hline \multicolumn{2}{|l|}{ Fibrosis } & \multirow{4}{*}{$\begin{array}{l}\mathrm{F}=3.683^{*} \\
\mathrm{p}=0.033^{*}\end{array}$} & \multirow{4}{*}{$\begin{array}{c}110.0 \\
(70.0 \pm 60.37) \\
150.0 \\
(141.9 \pm 70.66) \\
177.5 \\
(143.8 \pm 90.66) \\
\end{array}$} & \multirow{4}{*}{$\begin{array}{l}\mathrm{H}=7.114^{*} \\
\mathrm{p}=0.029^{*}\end{array}$} \\
\hline Absent & $\begin{array}{c}170.0 \\
(165.0 \pm 27.49)\end{array}$ & & & \\
\hline Mild & $\begin{array}{c}170.0 \\
(165.0 \pm 42.73)\end{array}$ & & & \\
\hline Severe & $\begin{array}{c}225.5 \\
(207.5 \pm 44.80)\end{array}$ & & & \\
\hline \multirow{2}{*}{\begin{tabular}{|c|}
$\begin{array}{l}\text { Bile duct injury } \\
\text { and proliferation }\end{array}$ \\
Absent
\end{tabular}} & \multirow{3}{*}{$\begin{array}{c}172.5 \\
(168.0 \pm 37.67) \\
170.0 \\
(187.0 \pm 59.03)\end{array}$} & \multirow{3}{*}{$\begin{array}{l}\mathrm{t}=0.970 \\
\mathrm{p}=0.353\end{array}$} & \multirow{3}{*}{$\begin{array}{c}120.0 \\
(115.3 \pm 69.27) \\
200.0 \\
(178.0 \pm 87.09)\end{array}$} & \multirow{3}{*}{$\begin{array}{c}\mathrm{U}=92.0^{*} \\
\mathrm{p}=0.008^{* *}\end{array}$} \\
\hline & & & & \\
\hline Present & & & & \\
\hline
\end{tabular}

\section{t: Student t-test F: ANOVA test r: Pearson coefficient}

U: Mann Whitney test H: Kruskal Wallis test

\#: Cases were excluded from the comparison (due to small sample size)

*: Statistically significant at $\mathrm{p} \leq 0.05$

**: Highly significant at $\mathrm{p} \leq 0.01$. 


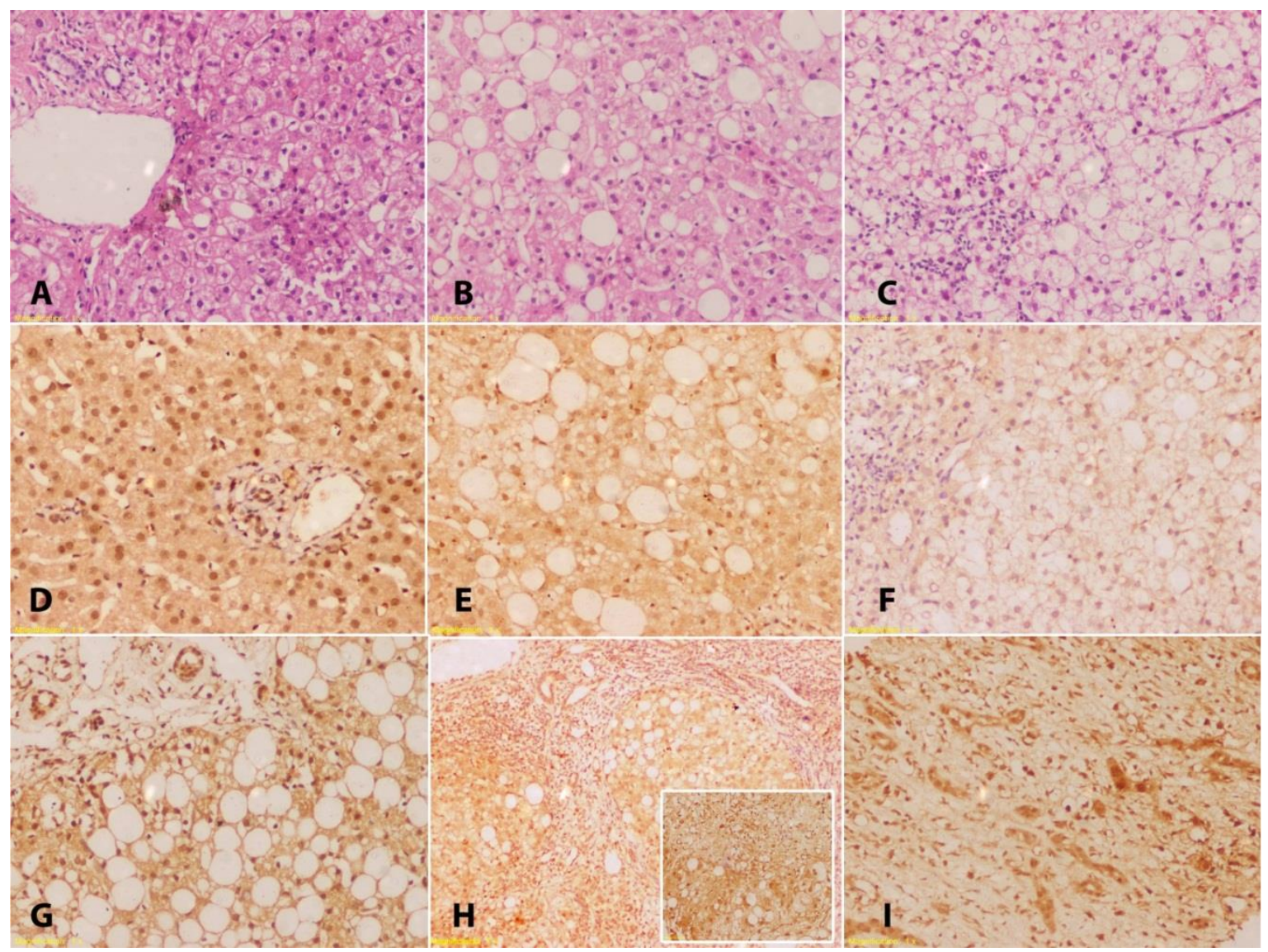

Figure (1): FXR immunohistochemical expression in the studied groups: (A) A case of normal liver tissue showed preserved lobular architecture and normal looking hepatocytes (H\&E x200). (B) A case of NAFL showed mild macrovesicular steatosis without hepatocytes ballooning or lobular inflammation (H\&E x200) (C) A case of NASH showed mild macrovesicular steatosis, hepatocytes ballooning and lobular inflammation (H\&E x200). (D) A case of normal liver tissue showed strong diffuse FXR expression in both hepatocytes and bile ducts (IHC x200). (E) A case of NAFL showed moderate FXR expression in hepatocytes (IHC x200). (F) A case of NASH showed mild FXR expression in hepatocytes (IHC x200). (G) A case of NASH with severe steatosis showed strong FXR expression in both hepatocytes and bile ducts (IHC x200). (H) A case of NASH with severe fibrosis with complete cirrhotic nodules showed strong FXR expression in both hepatocytes and bile ducts (IHC x100), (incited image showed strong FXR expression with severe fibrosis, IHC x200).(I) A case of NASH showed strong FXR expression in the proliferating and injured bile ducts (IHC x200).

\section{DISCUSSION}

The prevalence of NAFLD is alarmingly increasing worldwide with a bidirectional link between metabolic syndrome, DM, obesity and NAFLD ${ }^{(4)}$. In parallel to the effectiveness of anti-viral agents in the management of chronic viral hepatitis, NAFLD became the leading cause of chronic liver disease in different countries ${ }^{\left({ }^{(}\right)}$. Even more, previous studies reported that failing of obtained sustained virological response (SVR) after anti-viral agents could result from secondary fat accumulation ${ }^{(18,19)}$.

Therefore, there is a trend to identify effective strategies for the diagnosis and treatment of NAFLD. Changing lifestyle, weight loss and exercise along with the control of associated risk factors remains the cornerstone of the management of NAFLD. The main objective of pharmacological therapy is to prevent the progression of liver disease and cardiovascular complications ${ }^{(20)}$. FXR agonists are reported to play a role in the management of NAFLD ${ }^{(21)}$. However, the long-term effect of FXR agonists on the progression of the disease spectrum and how long should it be maintained with no adverse effect remains yet unclear. Therefore, the present study aimed to assess the immunohistochemical expression of FXR protein on different NAFLD spectrum and to compare the expression with the possible clinicopathological data.

The current study showed positive FXR nuclear staining in both hepatocytes and bile ducts in all normal liver tissue cases. FXR hepatocyte cytoplasmic expression was also noticed (16) and statistically analyzed. However, it showed non-significant association with the clinicopathological parameters. Also, there was no significant difference between different FXR cellular and subcellular localization in both NAFL and NASH groups. However, previous studies reported that hepatocyte cytoplasmic expression is the non-activated form that translocated to the nucleus 
to perform its function ${ }^{(8)}$. However, Lax et al. ${ }^{(22)}$ observed a cytoplasmic expression of FXR on colon cancer without focusing on its significant impact. In another study performed by Huang $\boldsymbol{e t}$ al. ${ }^{(16)}$, it was reported that the activated form of FXR was located in the cytoplasm without nuclear expression in the brain tissue. Therefore, the function of FXR subcellular localization could be varied according to the organ distribution. However, further studies are recommended to ascertain the value of FXR cytoplasmic hepatic localization in induction of hepatic steatosis and liver disease.

The detected FXR expression in normal liver tissue agreed with previous studies that highlighted the physiological role of FXR in regulating lipid metabolism, glucose homeostasis, and bile acid synthesis which is the final step of cholesterol catabolism through different molecular pathways ${ }^{(7,14,23)}$. Under physiological conditions, FXR was found to reduce liver steatosis and hyperlipidemia by suppressing de novo lipogenesis, inducing lipoprotein lipase activity, and promoting TG oxidation and clearance ${ }^{(24)}$.

The present study showed significantly decreased FXR hepatocyte and bile duct immunohistochmical expressions in the whole NAFLD spectrum cases group in comparison to normal liver group. This agreed with Yang $\boldsymbol{e t}$ al. ${ }^{(9)}$ and AguilarOlivos et al. ${ }^{(25)}$ who reported low FXR protein level in patients with NAFLD. Also, we found a significant decrease in FXR hepatocyte nuclear expression in NASH group compared to normal liver group which support other researchers who found that FXR deficiency induce pathologic manifestations of NASH $(\mathbf{1 0 , 1 1 )}$. Therefore, activation of FXR could be a therapeutic target for management of NAFLD progression and for treatment of NASH.

Interestingly, the current study showed no significant difference regarding FXR hepatocyte expression in NAFL and normal liver groups. On the other hand, FXR hepatocyte expression declined in a stepwise fashion from normal to NASH passing through simple steatosis group.

In NAFLD group, there was an inverse correlation between low FXR hepatocyte and bile duct expression with subsequently NAFLD progression and the elevated serum ALT/AST ratio. This highlights the anti-inflammatory role of FXR in liver injury proved with a previous study that used synthetic FXR agonist (WAY-362450) on animal model and it was found to significantly lower the serum level of liver functional enzymes, AST and ALT, and inflammatory chemokines, MCP-1 (Monocyte chemoattractant protein-1) expression and so significantly decrease inflammatory cell infiltration in the liver ${ }^{(21)}$. This also agreed with Sorbi et al. ${ }^{(26)}$ and Obika and Noguchi ${ }^{(27)}$ who reported the value of ALT/AST ratio as a powerful biomarker index as a part of the NAFLD liver fat score to assess diseased progression. Therefore, ALT/AST ratio could be a non-invasive indicator of NAFLD progression and also for further assessment of the impact of FXR agonists.

FXR hepatocyte nuclear overexpression was significantly associated with the moderate grade of steatosis. This agreed with Zhang et al. (28) who postulated that the long-term activation of FXR may increase fat mass and obesity in a mouse model of NAFLD. In addition, the current study showed a significant association between FXR hepatocyte nuclear expression and the severe stage of fibrosis. This disagreed with previous studies done on two rodent models to explore the antifibrotic activity of FXR ligand and found a beneficial effect of FXR and its agonists in preventing hepatic fibrosis ${ }^{(29)}$. On the other hand, Fickert et al. ${ }^{\left({ }^{30}\right)}$ detected the immunohistochemical expression of FXR in five mouse models and prototypic human fibrotic liver diseases and found that loss of FXR significantly reduces fibrosis only of the biliary type but has no impact on non-cholestatic liver fibrosis as there is no FXR expression in hepatic stellate cells (HSCs) and portal myofibroblasts (MFBs) detected in liver fibrosis. Moreover, other studies linked increased FXR expression to hepatic fibrogenesis and subsequent cirrhosis modulated by fibroblast growth factor 19 activation (FGF 19) ${ }^{(31,32)}$. The possible mechanisms are either disrupting BA metabolism or hepatic stem cell activation (33). Finally, the current study showed a significant association of FXR bile duct expression and presence of bile duct injury and proliferation which with the hepatic fibrosis could support the role of FXR in inducing cholangiocytes proliferation. This is supported by the positive correlation between FXR hepatocyte and bile duct expression in the current study. This agreed with An et al. ${ }^{(34)}$ who found that certain FXR agonist exacerbated bile ductular reaction. Hence, bile duct proliferation; biliary progenitor cells are the main players in hepatic fibrosis progression ${ }^{(35)}$.

\section{CONCLUSIONS}

The immunohistochemical expression of FXR might play a role in NAFLD progression that necessitates the integration of different hepatic and bile duct cellular localizations. Decreased FXR expression could lead to NAFLD disease progression. However, once NAFLD spectrum has developed, FXR hepatocyte and bile duct nuclear overexpression were associated with advanced steatosis and fibrosis. The inflammatory biomarkers (ALT \& AST) can be used as a non-invasive method for monitoring of the efficacy of FXR agonists in the treatment of NASH.

\section{REFERENCES}

1. Mitra S, De A, Chowdhury A (2020): Epidemiology of non-alcoholic and alcoholic fatty liver diseases. Transl Gastroenterol Hepatol., 5: 1-17. 
2. Contos M, Sanyal A (2002): The clinicopathologic spectrum and management of nonalcoholic fatty liver disease. Adv Anat Pathol., 9(1): 37-51.

3. Younossi Z, Koenig A, Abdelatif D et al. (2016): Global epidemiology of nonalcoholic fatty liver disease-Metaanalytic assessment of prevalence, incidence, and outcomes. Hepatology, 64(1): 73-84.

4. Rosato V, Masarone M, Dallio M et al. (2019): NAFLD and extra-hepatic comorbidities: Current evidence on a multi-organ metabolic syndrome. Int $\mathrm{J}$ Environ Res Public Health, 16(18): 1-26.

5. Tilg H, Effenberger $M$ (2020): From NAFLD to MAFLD: when pathophysiology succeeds. Nat Rev Gastroenterol Hepatol., 17(7): 387-388.

6. Kumar R, Priyadarshi R, Anand U (2020): Non-alcoholic fatty liver disease: Growing burden, adverse outcomes and associations. J Clin Transl Hepatol., 8(1): 76-86.

7. Zhang C, Wang $Z$, Feng $Q$ et al. (2020): Farnesoid $x$ receptor: A potential therapeutic target in multiple organs. Histol Histopathol., 35(12): 1403-1414.

8. Stofan M, Guo G (2020): Bile Acids and FXR: Novel Targets for Liver Diseases. Front Med., 7: 1-12.

9. Yang Z, Shen W, Sun H (2010): Effects of nuclear receptor FXR on the regulation of liver lipid metabolism in patients with non-alcoholic fatty liver disease. Hepatol Int., 4(4): 741-781.

10. Kong B, Luyendyk J, Tawfik O et al. (2009): Farnesoid x receptor deficiency induces nonalcoholic steatohepatitis in low-density lipoprotein receptor-knockout mice fed a highfat diet. J Pharmacol Exp Ther., 328(1): 116-22.

11. Armstrong L, Guo G (2017): Role of FXR in Liver Inflammation During Nonalcoholic Steatohepatitis. Curr Pharmacol Reports, 3(2): 92-100.

12. Klingenberg $M$, Groß $M$, Goyal A et al. (2017): The lncRNA CASC9 and RNA binding protein HNRNPL form a complex and co-regulate genes linked to AKT signaling. Hepatology, 777(5): 1-36.

13. Bedossa P, Poitou C, Veyrie $N$ et al. (2012): Histopathological algorithm and scoring system for evaluation of liver lesions in morbidly obese patients. Hepatology, 56(5): 1751-9.

14. Higashiyama H, Kinoshita $M$, Asano $S$ (2008): Immunolocalization of farnesoid $\mathrm{X}$ receptor $(\mathrm{FXR})$ in mouse tissues using tissue microarray. Acta Histochem., 110(1): 86-93.

15. Kumagai A, Fukushima J, Takikawa H et al. (2013): Enhanced expression of farnesoid $\mathrm{X}$ receptor in human hepatocellular carcinoma. Hepatol Res., 43(9): 959-69.

16. Huang $\mathrm{C}$, Wang $\mathrm{J}$, Hu W et al. (2016): Identification of functional farnesoid $\mathrm{X}$ receptors in brain neurons. FEBS Lett., 590(18):3233-3242.

17. Nortunen M, Väkiparta N, Porvari K et al. (2021): Pathophysiology of reflux oesophagitis: role of Toll-like receptors 2 and 4 and Farnesoid $\mathrm{X}$ receptor. https://pubmed.ncbi.nlm.nih.gov/33686512/

18. Noureddin M, Wong M, Todo T et al. (2018): Fatty liver in hepatitis $\mathrm{C}$ patients post-sustained virological response with direct-acting antivirals Prospective Study. World J Gastroenterol., 24(11): 1269-1277.

19. Ghoneim S, Butt M, Trujillo $S$ et al. (2020): FIB-4 Regression With Direct-Acting Antiviral Therapy in Patients With Hepatitis C Infection: A Safety-Net Hospital Experience. Front Med., 7: 1-8.
20. Pennisi G, Celsa C, Spatola F et al. (2019): Pharmacological Therapy of Non-Alcoholic Fatty Liver Disease: What Drugs Are Available Now and Future Perspectives. Int J Environ Res Public Health, 16(22): 4334.

21. Zhang S, Wang J, Liu Q et al. (2009): Farnesoid X receptor agonist WAY-362450 attenuates liver inflammation and fibrosis in murine model of non-alcoholic steatohepatitis. $J$ Hepatol., 51(2): 380-388.

22. Lax S, Schauer G, Prein K et al. (2012): Expression of the nuclear bile acid receptor/farnesoid $\mathrm{X}$ receptor is reduced in human colon carcinoma compared to nonneoplastic mucosa independent from site and may be associated with adverse prognosis. Int J Cancer, 130(10388):2232-2239.

23. Sinal C, Tohkin M, Miyata $M$ et al. (2000): Targeted disruption of the nuclear receptor FXR/BAR impairs bile acid and lipid homeostasis. Cell, 102(6): 731-744.

24. Jiao Y, Lu Y, Li X (2015): Farnesoid X receptor: A master regulator of hepatic triglyceride and glucose homeostasis. Acta Pharmacol Sin., 36(1): 44-50.

25. Aguilar-Olivos N, Carrillo-Córdova D, Oria-Hernández J et al. (2015): The nuclear receptor FXR, but not LXR, upregulates bile acid transporter expression in non-alcoholic fatty liver disease. Ann Hepatol., 14(4): 487-493.

26. Sorbi D, Boynton J, Lindor K (1999): The Ratio of Aspartate Aminotransferase to Alanine Aminotransferase: Potential Value in Differentiating Nonalcoholic Steatohepatitis From Alcoholic Liver Disease. Am J Gast4roenterol., 94(4):1018-1022.

27. Obika M, Noguchi H (2012): Diagnosis and evaluation of nonalcoholic fatty liver disease. Exp Diabetes Res., 2012:145754.

28. Zhang Y, Ge X, Heemstra L et al. (2012): Loss of FXR protects against diet-induced obesity and accelerates liver carcinogenesis in ob/ob mice. Mol Endocrinol., 26(2):272280.

29. Fiorucci S, Antonelli E, Rizzo G et al. (2004): The nuclear receptor SHP mediates inhibition of hepatic stellate cells by FXR and protects against liver fibrosis. Gastroenterology, 127(5): 1497-1512.

30. Fickert P, Fuchsbichler A, Moustafa T et al. (2009): Farnesoid X receptor critically determines the fibrotic response in mice but is expressed to a low extent in human hepatic stellate cells and periductal myofibroblasts. Am J Pathol., 175(6): 2392-2405.

31. Inagaki T, Choi M, Moschetta A et al. (2005): Fibroblast growth factor 15 functions as an enterohepatic signal to regulate bile acid homeostasis. Cell Metab., 2(4): 217-225.

32. Alvarez-sola G, Uriarte I, Latasa $M$ et al. (2018): BBA Molecular Basis of Disease Bile acids , FGF15 / 19 and liver regeneration: From mechanisms to clinical. BBA - Mol Basis Dis., 1864(4): 1326-1334.

33. Schumacher J, Guo G (2016): Regulation of Hepatic Stellate Cells and Fibrogenesis by Fibroblast Growth Factors. Biomed Res Int., 2016: 8323747.

34. An P, Wei G, Huang P et al. (2020): A novel non-bile acid FXR agonist EDP-305 potently suppresses liver injury and fibrosis without worsening of ductular reaction. Liver Int., 40(7):1655-1669.

35. Tanwar S, Rhodes F, Srivastava A et al. (2020): Inflammation and fibrosis in chronic liver diseases including nonalcoholic fatty liver disease and hepatitis C. World J Gastroenterol., 26(8): 109-133. 